\title{
A literature-based algorithm for the assessment, management, and monitoring of drug-induced QTc prolongation in the psychiatric population
}

This article was published in the following Dove Press journal: Neuropsychiatric Disease and Treatment

\author{
M Zolezzi' \\ L Cheung ${ }^{2}$ \\ 'Division of Clinical Pharmacy and \\ Practice, College of Pharmacy, Qatar \\ University, Doha, Qatar; '2Pharmacy \\ Department, Grey Nuns Community \\ Hospital, Edmonton, AB, Canada
}

Background: Certain psychotropics and a number of other medications used to treat medical conditions in psychiatric patients can increase the risk of prolonging the corrected QT (QTc) interval on the electrocardiogram, which puts patients at risk of life-threatening ventricular arrhythmias such as torsades de pointes. Pharmacists are often consulted about medications which are known to prolong the QTc interval. Although this information is often accessible, advising how to identify, assess, manage, and refer psychiatric patients at risk for drug-induced QTc prolongation is more challenging.

Objectives: The objective of this project was first to review the literature, which describes guidelines and recommendations for the assessment and management of drug-induced QTc prolongation, and then to design an algorithm to be used by pharmacists working closely with mental health professionals or who provide care to psychiatric patients.

Methods: A review of the literature was undertaken. Predefined keywords were used to perform the database search in MEDLINE, EMBASE, and International Pharmaceutical Abstracts to identify reviews, reports and guidelines on the assessment, prevention and monitoring of druginduced QTc prolongation with an emphasis on psychotropic medications and management in the psychiatric population.

Results: The electronic database search retrieved 637 relevant citations. These were initially screened by title and all duplicates were removed. The abstracts were then reviewed for relevancy based on the inclusion/exclusion criteria. Additional citations were retrieved from the bibliography of the articles identified in the initial search. A total of 79 articles describing QTc prolongation in the psychiatric population were thoroughly examined, but only 31 articles were selected to guide the development of the algorithm.

Conclusion: The literature-based algorithm developed provides a stepped-based approach for the assessment, monitoring, and management of drug-induced QTc prolongation in the psychiatric population. The algorithm may assist mental health clinicians in the decision-making process when psychiatric patients are prescribed medications known to increase the QTc interval. Keywords: drug-induced arrhythmias, QT interval, torsades de pointes, guidelines, protocol, algorithm, mental, patients

\section{Background}

Prolongation of the QT interval is a concern for all clinicians as it can lead to fatal consequences, such as sudden cardiac death (SCD). ${ }^{1}$ Among psychiatric patients, SCD is one of the major causes of premature mortality. ${ }^{2-5}$ Psychotropic medications have been implicated in the increased risk of SCD among psychiatric patients, primarily in view of their potential for prolonging the QT interval. ${ }^{3-6}$ Although relatively rare, prolongation 
of the QT interval can be followed by a life-threatening polymorphic ventricular tachyarrhythmia called torsades de pointes (TdP). ${ }^{7,8}$ The mortality risk associated with TdP is high, estimated to be approximately $10 \%{ }^{8}$

$\mathrm{TdP}$ is commonly associated with hereditary or acquired forms of prolonged QT interval (also known as long QT syndrome [LQTS]). ${ }^{1}$ Mutations of the human hERG protein ion channels (potassium, calcium, and sodium), which contribute to the electrical activity of the heart, result in congenital LQTS (cLQTS). ${ }^{9}$ Acquired LQTS is almost always due to blockage or inhibition of the inward potassium rectifier (IKr) channel, which is critical in the phase 3 repolarization of the cardiac action potential. ${ }^{10}$ As with cLQTS, most cases of drug-induced long QT and TdP result from an action of the drugs on the ion channel proteins encoded by the $h E R G$ gene that is responsible for the $\mathrm{IKr}$ repolarizing current. ${ }^{11}$ A recent study by Itoh et al reported that up to $28 \%$ of patients with drug-induced QT prolongation carry mutations causing the LQTS. ${ }^{12}$ The concept of repolarization reserve has been employed to account for individual differences in the susceptibility to develop TdP with drugs or conditions known to affect the heart's potassium currents. ${ }^{11}$

The potential risk of TdP raises concerns among health care providers when prescribing medications known to inhibit hERG IKr channel, particularly in patients who may be predisposed. ${ }^{13}$ In addition, various psychotropic drugs have also been shown to inhibit inward ionic currents mediated by sodium and calcium. ${ }^{14,15}$ Besides psychotropic medications, other medications commonly used by psychiatric patients have also been implicated in prolonging the QT interval such as antiarrhythmic medications, antibiotics, antifungals, and antiemetic medications, some of which were removed from the market due to associated TdP. ${ }^{13}$

Studies have demonstrated that clinicians are often unable to identify TdP risk factors or medications that can prolong the QT interval. ${ }^{16,17}$ Fongemie et al reported discordance among cardiologists in the decision-making process when corrected QT (QTc)-prolonging medications were to be used. ${ }^{17}$ Furthermore, in daily practice, because of an ever-increasing number of medications available and other nondrug factors that must be accounted for during a risk assessment, clinicians may face difficulties on how to assess, manage, monitor and refer patients at risk of QTc prolongation.

Pharmacists are often consulted about medications that are known to prolong the QTc interval. To be meaningful, advice provided should extend beyond simple information about the potential for QT interval prolongation with a particular medication. However, this information may be more challenging for pharmacists to retrieve and difficult to interpret, particularly when caring for mental health patients who often have complex treatment regimens and who are often on poly-pharmacy. As such, the purpose of this paper was to summarize the literature describing guidelines and recommendations for the assessment and management of drug-induced QTc prolongation in psychiatric patients, and to develop an algorithm to guide all clinicians in the decisionmaking process when psychiatric patients are prescribed medications with the potential of prolonging the QTc interval.

\section{Methods}

A literature search was conducted to identify pertinent published literature. Three databases were searched: MEDLINE (Ovid), from 1946 to November 2017, EMBASE, from 1974 to November 2017, and International Pharmaceutical Abstracts, from 1970 to November 2017. The following search strategy was used to identify relevant literature: ("guideline"'[All Fields] OR "guidelines as topic"[MeSH Terms] OR "guidelines"[All Fields]) AND ("organization and administration"[MeSH Terms] OR (“organization”[All Fields] AND “administration"[All Fields]) OR “organization and administration"[All Fields] OR “management”[All Fields] OR “disease management"[MeSH Terms] OR (“disease"[All Fields] AND “management"[All Fields]) OR “disease management”[All Fields]) AND QTc[All Fields] AND interval[All Fields] AND prolongation[All Fields] AND ("patients"[MeSH Terms] OR "patients"[All Fields]) AND ("mental disorders"[MeSH Terms] OR ("mental"[All Fields] AND “disorders"[All Fields]) OR “mental disorders"[All Fields] OR ("mental”[All Fields] AND “illness”[All Fields]) OR “mental illness”[All Fields]) AND (“psychiatry”[MeSH Terms] OR "psychiatry”[All Fields] OR "psychiatric"[All Fields]) AND ("pharmaceutical preparations"[MeSH Terms] OR ("pharmaceutical"[All Fields] AND “preparations”[All Fields]) OR “pharmaceutical preparations"[All Fields] OR “medications”[All Fields]).

The initial screening consisted of reviewing the relevance of the article titles and then reviewing the abstracts of the articles that passed the initial title screening. Articles describing individual studies or systematic reviews discussing assessment, risk stratification, monitoring, and prevention of QTc prolongation in the psychiatric population were included. Additional citations were retrieved from the bibliography of the articles identified in the initial search. Articles written in languages other than English, for which full-text articles could not be obtained or published before 
2010, were excluded. This timeline restriction ensured that only the most updated research findings were used in guiding the development of the algorithm.

\section{Results}

The electronic database search retrieved 637 relevant citations. These were initially screened by title and all duplicates were removed. A total of 79 articles describing QTc prolongation in the psychiatric population were thoroughly examined, but only 31 articles were selected to guide the development of the algorithm. Based on the inclusion/ exclusion criteria described previously, the articles were grouped into the following categories:

1. Articles describing individual studies discussing risk factor assessment, risk stratification, and/or monitoring of the QTc interval in the psychiatric population. A total of 14 articles were included, a summary of the findings of these studies is presented in Table $1 .{ }^{18-31}$

Table I Articles reviewing QTc prolongation assessment and risk stratification among psychiatric patients

\begin{tabular}{|c|c|}
\hline $\begin{array}{l}\text { Author, year } \\
\text { of publication }\end{array}$ & Summary of findings \\
\hline $\begin{array}{l}\text { Ojero-Senard } \\
\text { et al, } 2017^{18}\end{array}$ & $\begin{array}{l}\text { Notifications from a pharmacovigilance database were collected for patients on SRIs with QTc prolongation. QTc prolongation } \\
\text { was only associated with citalopram and escitalopram and was noted as not being a side effect of SRIs. }\end{array}$ \\
\hline $\begin{array}{l}\text { Barbui et al, } \\
2016^{19}\end{array}$ & $\begin{array}{l}\text { This cross-sectional survey showed that antipsychotic poly-pharmacy and antipsychotic dosing were associated with QTc } \\
\text { interval prolongation. }\end{array}$ \\
\hline $\begin{array}{l}\text { Danielsson } \\
\text { et al, } 2016^{20}\end{array}$ & $\begin{array}{l}\text { This matched case-control register study showed that the CredibleMeds }{ }^{\circledR} \text { system of TdP classification risk predicted drug- } \\
\text { related risk for mortality in the elderly. }\end{array}$ \\
\hline $\begin{array}{l}\text { Nose et al, } \\
2016^{21}\end{array}$ & $\begin{array}{l}\text { This cross-sectional study was conducted at several psychiatric centers to measure the frequency of QTc prolongation and } \\
\text { associated risk factors. Risk factors that were associated with QTc prolongation included female sex, age, heart rate, alcohol } \\
\text { and/or substance abuse, cardiovascular disease, cardiovascular drug treatment, drug overdose, and polypharmacy. Data support } \\
\text { current guidelines that recommend avoiding the concurrent use of two or more antipsychotics and the link between citalopram } \\
\text { and QTc prolongation, which necessitates routine ECG monitoring. }\end{array}$ \\
\hline $\begin{array}{l}\text { Schächtele et al, } \\
2016^{22}\end{array}$ & $\begin{array}{l}\text { Hospital discharge prescriptions in a geriatric cohort were assessed for presence of QT-prolonging medications. A considerable } \\
\text { proportion of QTc-prolonging medications with higher risk (as per }\left(\text { redibleMeds }^{\circledR}\right) \text { could only be detected by using more than } \\
\text { one classification system. Adaptation of international classifications can improve identification of patients at risk. }\end{array}$ \\
\hline $\begin{array}{l}\text { Poncet et al, } \\
2015^{23}\end{array}$ & $\begin{array}{l}\text { An analytical model estimating the cost effectiveness of routine ECG screening to identify QTc prolongation in psychiatric hospitals } \\
\text { revealed that performing systematic ECG at admission helped reduce the number of sudden cardiac deaths in a cost-effective fashion. }\end{array}$ \\
\hline Rabkin, $2015^{24}$ & $\begin{array}{l}\text { This literature review suggests that the association of increasing age and female sex with greater QT intervals necessitates } \\
\text { awareness of the QTc prior to use of psychotropics and to measure QTc after initiation of therapy. }\end{array}$ \\
\hline $\begin{array}{l}\text { Takeuchi et al, } \\
2015^{25}\end{array}$ & $\begin{array}{l}\text { This systematic literature review claims that current evidence does not confirm that antipsychotic poly-pharmacy prolongs QTc, } \\
\text { though poly-pharmacy with high-risk QTc-prolonging medications may increase the risk. Authors advise clinicians to remain } \\
\text { conservative in prescribing antipsychotic poly-pharmacy considering that the clinical benefit of antipsychotic poly-pharmacy is lacking. }\end{array}$ \\
\hline $\begin{array}{l}\text { Shah et al, } \\
2014^{26}\end{array}$ & $\begin{array}{l}\text { Authors conclude that ECG monitoring when starting an antipsychotic in the absence of cardiovascular risk factors is not } \\
\text { necessary. ECG monitoring is recommended if a patient has cardiovascular risk factors, if the antipsychotic is high-risk for TdP } \\
\text { or sudden death, or if a patient has overdosed on an antipsychotic. }\end{array}$ \\
\hline $\begin{array}{l}\text { Girardin et al, } \\
2013^{27}\end{array}$ & $\begin{array}{l}\text { This cross-sectional study measured the prevalence of drug-induced QT prolongation as well as associated risk factors in } \\
\text { patients admitted to a psychiatric hospital. QTc prolongation and arrhythmia occurrence increase when specific psychotropic } \\
\text { drugs are started in patients with hypokalemia, abnormal T-wave morphology, HCV infection, and HIV infection. }\end{array}$ \\
\hline $\begin{array}{l}\text { Krantz et al, } \\
2013^{28}\end{array}$ & $\begin{array}{l}\text { This study suggests that an ECG-based intervention in methadone maintenance can decrease the QTc interval in high-risk } \\
\text { patients and that clinical characteristics alone are inadequate to identify patients who need ECG monitoring. }\end{array}$ \\
\hline $\begin{array}{l}\text { Tran and } \\
\text { Dishman, } 2012^{29}\end{array}$ & $\begin{array}{l}\text { Authors provide a review of citalopram-induced QTc prolongation and how to manage patients at risk, particularly those at high } \\
\text { citalopram doses (eg. } \geq 40 \mathrm{mg} \text { in patients older than } 60 \text { years, or } \geq 20 \mathrm{mg} \text { in patients younger than } 60 \text { years). }\end{array}$ \\
\hline $\begin{array}{l}\text { Wenzel-Seifert } \\
\text { et al, } 201 \mathrm{I}^{30}\end{array}$ & $\begin{array}{l}\text { The risk of QTc prolongation and TdP associated with common antipsychotics is reviewed. In addition, patients' risk factors for } \\
\text { QTc prolongation and TdP are reviewed, including age over } 65 \text { years, pre-existing cardiovascular disease, bradycardia, female sex, } \\
\text { hypokalemia, hypomagnesemia, supratherapeutic/toxic serum concentration, or simultaneous administration of other drugs that } \\
\text { delay repolarization or interfere with drug metabolism. }\end{array}$ \\
\hline $\begin{array}{l}\text { Yang et al, } \\
201 \mathrm{I}^{31}\end{array}$ & $\begin{array}{l}\text { Results of this cross-sectional naturalistic study among hospitalized patients with schizophrenia on long-term antipsychotics, } \\
\text { revealed QTc prolongation was higher in women than in men. It was also found that clozapine led to more profound QTc } \\
\text { prolongation than atypical antipsychotics and risperidone. Predictors of QTc prolongation identified included comorbid } \\
\text { cardiovascular disease, antipsychotic types, sex, and age. }\end{array}$ \\
\hline
\end{tabular}


2. Articles describing guidelines or protocols for preventing, monitoring or managing drug-induced QTc prolongation in the psychiatric population. A total of nine articles were included and a summary of the recommendations provided in these articles is presented in Table 2. ${ }^{32-40}$

3. Review articles about drug-induced QTc prolongation risk stratification in nonpsychiatric patients from which relevant recommendations were extrapolated to support development of the algorithm. A total of eight review articles were included and these are summarized in Table $3 .^{41-48}$

As illustrated in Figure 1, the literature-based algorithm developed provides a stepped-based approach for the assessment, management, and monitoring of psychotropicinduced QTc prolongation in the psychiatric population. The algorithm includes a set of questions which facilitate the decision-making process and the evidence that supports the decision points.

\section{Step I: assessing the medication risk}

The starting point is assessing the medication prescribed. When prescribing a psychotropic agent or any other medication for psychiatric patients who are taking psychotropic medications, particularly antipsychotics or antidepressants, the first step consists of assessing the prescribed drug. ${ }^{18,20,22,29,30,34,38,42,47}$ The most comprehensive and easily accessible reference source for medications known or suspected to cause QT prolongation is CredibleMeds ${ }^{\circledR}$ accessible through the world wide web (WWW) at www.crediblemeds.org. ${ }^{49}$ This website is maintained by AZCERT (The Arizona Center for Education and Research on Therapeutics), a nonprofit organization, that uses a rigorous, systematic risk stratification process to determine a medication's likelihood to cause QT prolongation or TdP. ${ }^{50}$ The evidence on this website is monitored closely and updated frequently. Clinicians can register and subscribe to updates from the website. CredibleMeds ${ }^{\circledR}$ is also available through a mobile application which can easily be accessed by clinicians on their cell phones, iPads or other pocket devices.

CredibleMeds ${ }^{\circledR}$ classifies medications into four categories: Category 1 Drugs, those with known risk of TdP; these drugs prolong the QT interval and have an associated known risk of TdP even when taken as recommended. Category 2 Drugs,

Table 2 Articles describing guidelines and protocols for assessing, monitoring, preventing or managing drug-induced QTc prolongation in the psychiatric population

\begin{tabular}{|c|c|}
\hline $\begin{array}{l}\text { Author, year of } \\
\text { publication }\end{array}$ & Summary of findings \\
\hline Wahidi et al, $2016^{32}$ & $\begin{array}{l}\text { Two case reports of TdP in patients on parenteral antipsychotics were reviewed and authors proposed practice guidelines } \\
\text { for dosing parenteral antipsychotics in order to avoid TdP during the control of agitation at psychiatric hospitals. }\end{array}$ \\
\hline Chou et al, $2014^{33}$ & $\begin{array}{l}\text { This guideline, based on a systematic review of methadone safety, provides recommendations developed by a } \\
\text { multidisciplinary expert panel. Safe use of methadone requires clinical skills and knowledge on use of methadone to mitigate } \\
\text { potential risks, including serious risks related to risk of overdose and cardiac arrhythmias. }\end{array}$ \\
\hline Fanoe et al, $2014^{34}$ & $\begin{array}{l}\text { In this review, data from various authorities on the risk of arrhythmia associated with psychotropic medications were } \\
\text { categorized into three risk categories. A clinical algorithm to reduce the risk of fatal arrhythmia in patients treated with } \\
\text { psychotropics is proposed. The algorithm integrates the risk categories and risk factors and suggests follow-up parameters } \\
\text { and timelines. }\end{array}$ \\
\hline $\begin{array}{l}\text { Pacciardi et al, } \\
2013^{35}\end{array}$ & $\begin{array}{l}\text { Authors summarized evidence-based safety considerations during the treatment of acute agitation with intramuscular } \\
\text { antipsychotic medications in psychiatric patients. }\end{array}$ \\
\hline $\begin{array}{l}\text { De Heart et al, } \\
2011^{36}\end{array}$ & $\begin{array}{l}\text { This review evaluated the quality and content of various screening guidelines published between } 2000 \text { and } 2010 \text { for } \\
\text { cardiovascular risk in schizophrenia. }\end{array}$ \\
\hline Martin et al, 20I I ${ }^{37}$ & $\begin{array}{l}\text { A multidisciplinary expert panel concluded that treatment programs should have a cardiac risk management plan } \\
\text { incorporating clinical assessment, ECG assessment, risk stratification, and prevention of drug interactions and should strongly } \\
\text { consider risk minimization strategies that are patient-specific (eg, patient monitoring, ECG, adjusting methadone dosing). }\end{array}$ \\
\hline $\begin{array}{l}\text { Nielsen et al, } \\
201 I^{38}\end{array}$ & $\begin{array}{l}\text { This article reviewed the mechanisms of QTc prolongation and the risk with antipsychotics, along with several clinical } \\
\text { recommendations. }\end{array}$ \\
\hline $\begin{array}{l}\text { Fishman et al, } \\
2010^{39}\end{array}$ & $\begin{array}{l}\text { Six broad recommendations based on evidence were developed by a working group of experts jointly convened by the } \\
\text { National Heart, Lung and Blood Institute and the Heart Rhythm Society to address and recommend research directions and } \\
\text { strategies in prediction and prevention of sudden cardiac death. }\end{array}$ \\
\hline $\begin{array}{l}\text { Modesto-Lowe } \\
\text { et al, } 2010^{40}\end{array}$ & $\begin{array}{l}\text { Retrospective analyses found that patients who develop TdP often have multiple risk factors, including high methadone doses, } \\
\text { use of other medications that cause QTc prolongation, and electrolyte abnormalities. As such, guidelines are presented for } \\
\text { initiating methadone in opioid treatment and pain populations. }\end{array}$ \\
\hline
\end{tabular}

Abbreviations: ECG, electrocardiogram; TdP, torsades de pointes; QTc, corrected QT. 
Table 3 Review articles about QTc prolongation (not specifically in the psychiatric population) included in the development of the algorithm

\begin{tabular}{|c|c|}
\hline $\begin{array}{l}\text { Author, year of } \\
\text { publication }\end{array}$ & Summary of findings \\
\hline $\begin{array}{l}\text { Institute for Safe } \\
\text { Medication Practices } \\
\text { Canada }^{\circledR}, 2017^{41}\end{array}$ & $\begin{array}{l}\text { Institute for Safe Medication Practices Canada }{ }^{\circledR} \text { (ISMP Canada) developed an evidence-based tool to help pharmacists } \\
\text { evaluate and communicate QT prolongation risk. }\end{array}$ \\
\hline Tisdale, $2016^{42}$ & $\begin{array}{l}\text { This article described the important role that pharmacists play in minimizing the risk of drug-induced QTc prolongation } \\
\text { and TdP. This article reviews clinical assessment of risk of QTc prolongation (via the QTc interval prolongation risk } \\
\text { score), drug interactions that increase risk of TdP, and dose reductions of renally eliminated QTc-prolonging drugs in } \\
\text { patients with kidney disease. }\end{array}$ \\
\hline Jardin et al, $2014^{43}$ & $\begin{array}{l}\text { This retrospective analysis assessed risk factors for TdP in hospitalized patients receiving } \geq I \text { QTc-prolonging } \\
\text { medication. The following risk factors were associated with significant QTc prolongation: female sex, LVEF }<40 \% \text {, and } \\
\text { cardiac arrest. }\end{array}$ \\
\hline Tisdale et al, $2014^{44}$ & $\begin{array}{l}\text { The authors described a computerized clinical decision support system developed to alert pharmacists to drugs that } \\
\text { lead to QTc prolongation among patients admitted to coronary care units at moderate/high risk of QTc prolongation. } \\
\text { When alerted, pharmacists were to contact prescribers to decrease risk of TdP. The use of this system resulted in a } \\
\text { significant reduction in the prescribing of QT-prolonging medications. }\end{array}$ \\
\hline Haugaa et al, $2013^{45}$ & $\begin{array}{l}\text { This institution-wide QT alert system was used to alert prescribers to patients with a QTc of over } 500 \text { ms. Mortality } \\
\text { was increased among those with increasing pro-QTc scores, which was an independent predictor of mortality. }\end{array}$ \\
\hline Tisdale et al, $2013^{46}$ & $\begin{array}{l}\text { A prospective observational study was conducted on } 900 \text { patients admitted to cardiac care units to develop and validate } \\
\text { a risk scoring system that could predict patients at highest risk of developing QTc prolongation. The tool is used to } \\
\text { distinguish whether patients are at low, medium, or high risk of QTc interval prolongation based on a score that is } \\
\text { obtained by number of risk factors and their weighting. }\end{array}$ \\
\hline Nachimuthu et al, $2012^{47}$ & $\begin{array}{l}\text { This article reviewed the mechanism of drug-induced QT prolongation, risk factors for TdP, culprit drugs, prevention, } \\
\text { and monitoring of prolonged drug-induced QT prolongation and treatment strategies. }\end{array}$ \\
\hline Drew et al, $2010^{48}$ & $\begin{array}{l}\text { This scientific statement reviewed the risk, ECG monitoring, and management of drug-induced LQTS. Authors reviewed } \\
\text { signs of arrhythmia, mechanisms of acquired LQTS, drug combinations known to cause TdP, risk factors/exacerbating } \\
\text { conditions, methods to monitor QT intervals, and management of QT prolongation and TdP. }\end{array}$ \\
\hline
\end{tabular}

Abbreviations: LQTS, long QT syndrome; LVEF, left ventricular ejection fraction; QTc, corrected QT; TdP, torsades de pointes.

those with possible risk of TdP; these drugs have the potential to cause QT prolongation, but there is a lack of evidence for TdP risk. Category 3 Drugs, those with conditional risk of TdP; these drugs are associated with TdP but only under certain circumstances or in patients with certain "at-risk" characteristics. Category 4 Drugs, those to be avoided in patients with cLQTS. ${ }^{50}$ Currently, 57 medications are on the list of drugs known to cause TdP. Another 92 are on the list with "possible risk of TdP" and 43 are on the "conditional risk" list. Two hundred and twenty-four medications are on the list of "drugs to avoid" for patients with cLQTS. ${ }^{50}$

\section{Step 2: assessing the prescribed medication dose, route of administration, and drug interactions}

For the majority ofQT-prolonging drugs, risk increases as a function of dose and plasma drug concentration. ${ }^{19,21,22,25,30,37,38,42,43,48}$ It has been recognized that drug plasma concentrations could be affected by multiple factors including dose, formulation form, route, frequency, administration time, drug-drug interaction, food-drug interaction, genetics, sex, age, body weight, pregnancy, circadian rhythms, comorbidities, pathophysiology status, and smoking. ${ }^{51}$ As such, depending on the type of medication used, weight-based dosing should be considered particularly for populations who are more vulnerable to increased plasma levels if not dosed according to weight (eg, elderly). ${ }^{52}$

The route of administration can also have an effect on the QT-prolonging extent of a drug, as medications administered intravenously tend to have higher potential of causing QT prolongation as opposed to oral administration. ${ }^{30,32,35}$ Intravenous administration can be associated with higher drug concentrations and thus greater cardiac exposure than corresponding oral dosing. ${ }^{47}$ Finally, rapid infusion of a QT-prolonging medication is also a risk factor for QT prolongation. ${ }^{30,42,43}$ Conditions that lead to elevated plasma concentrations of QTc interval-prolonging drugs increase the risk of drug-induced TdP, including pharmacokinetic drug interactions and inadequate dose adjustment of renally eliminated QTc interval-prolonging drugs in patients with acute kidney injury or chronic kidney disease. ${ }^{42,47}$ In addition, competitive protein binding can potentially cause increased serum 


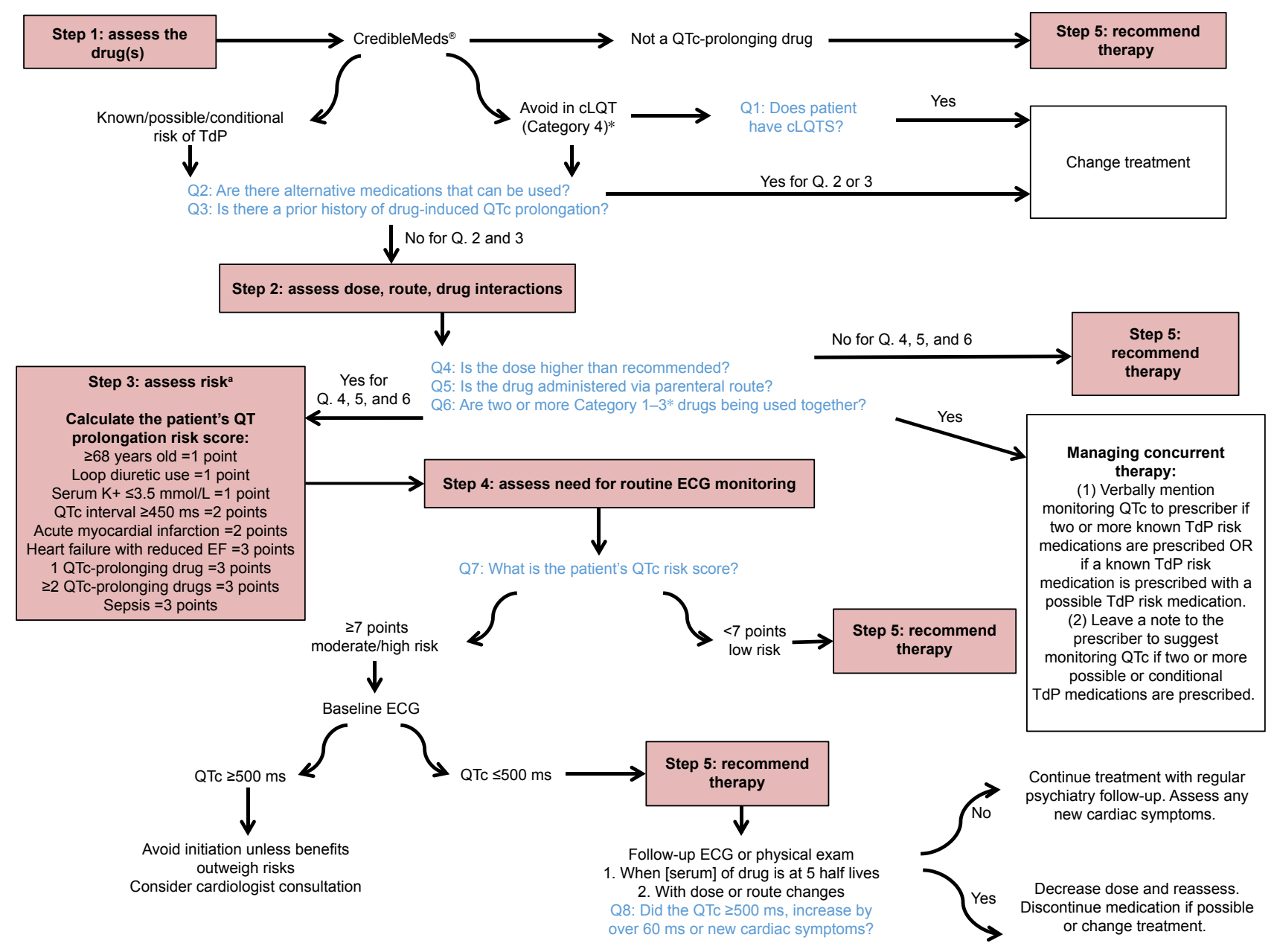

Figure I A literature-based algorithm for the assessment, management and monitoring of drug-induced QTc prolongation. Notes: *As per CredibleMeds ${ }^{\circledR}$. as per Tildale et al. ${ }^{46}$

Abbreviations: cLQTS, congenital long QT syndrome; ECG, electrocardiogram; EF, ejection fraction; QTc, corrected QT; TdP, torsades de pointes.

levels of medications that prolong QTc when combined with seemingly benign medications that are highly protein bound, such as acetylsalicylic acid and sodium valproate, and some herbal preparations..$^{30} \mathrm{~A}$ comprehensive and easily accessed reference source in the WWW for pharmacokinetic interactions is available from Medscape ${ }^{\circledR}$ at $\mathrm{https}$ ://reference. medscape.com/drug-interactionchecker. CredibleMeds ${ }^{\circledR}$ also lists medication combinations which should be used with caution by identifying medications that could cause additive pharmacodynamic interactions with psychotropic medications that prolong QTc. ${ }^{49,50}$

\section{Step 3: assessing the patient's risk of QTc prolongation and TdP}

Electrolyte abnormalities, particularly hypokalemia, hypomagnesemia, and hypocalcemia, are known risk factors for QT prolongation. ${ }^{27,30,34,40-43,47,48}$ Drug-induced QTc prolongation also occurs more commonly in females than in males, and the effects are more pronounced in older patients above the age of 65 years. . $0,22,23,30,31,34,42,43,47$ Patients with an underlying heart disease including cLQTS, myocardial ischemia, cardiomyopathy, cardiac arrhythmias, bradycardia, or congestive heart failure are also predisposed to QT prolongation in comparison to healthy counterparts. $22,26,27,30,31,34,37,38,42,43,48$ Because many hospitalized patients often have other risk factors for a proarrhythmic response, such as older age with an underlying heart disease who may also have renal or hepatic dysfunction, electrolyte abnormalities, or bradycardia and to whom drugs may be administered rapidly via the intravenous route, administration of a QT-prolonging drug to a hospitalized population may be more likely to cause TdP than administration of the same drug to an outpatient population. ${ }^{32,35,43,48,49}$

There are three manual stratification tools published in the literature that clinicians can use to determine individual 
QTc-prolongation risk. ${ }^{45,46,49}$ Of these, only the one developed by Tisdale et al has been validated. ${ }^{46}$ This risk scoring tool allows quantification of a patient's risk based on the presence or absence of a total of ten possible risk factors, with a maximum possible score of 21 . This scoring system classifies patients as low, medium or highrisk (QTc score $\leq 7$, $8-10$ or $\geq 11$, respectively). In a subsequent study, the same authors were able to demonstrate that incorporating this validated risk scoring tool into a decision support tool system influenced the prescribing of QT-prolonging drugs and reduced the risk of QTc interval prolongation in hospitalized patients with TdP risk factors. ${ }^{44}$

\section{Step 4: determining the need for measuring the QT interval}

Although monitoring of the QT interval by electrocardiogram (ECG) prior to treatment with QT-prolonging drugs is often recommended by the drug manufacturers, indications for obtaining a baseline ECG and/or routine ECG monitoring are mixed in the literature. ${ }^{23,26,28,34,36,47,53}$ Although it may be easier in an inpatient setting, a wearable remote monitoring system has been recommended for the identification of subjects with cLQTS or at risk for drug-induced LQTS in outpatient settings. ${ }^{54}$ De Hert et al conducted a systematic review of various guidelines for cardiovascular risk with antipsychotic medications and found that $50 \%$ of guidelines support ECG monitoring for psychotropic agents with the potential to prolong the QTc interval. ${ }^{36}$ Based on the risk assessment, patients with a QTc risk score of 7 when using the validated risk scoring tool developed by Tisdale et al, or those taking high-risk drug combinations, should have an ECG when the plasma concentration of a new QT-prolonging agent reaches steady state (ie, five half-lives following initiation). ${ }^{42}$

Magnesium and potassium levels should also be checked with ECG. ${ }^{46}$ When following-up on an ECG done at steady state, drug-induced QT prolongations of $<25 \mathrm{~ms}$ are considered insignificant by some clinicians, though the increase of $60 \mathrm{~ms}$ or QTc intervals of over $500 \mathrm{~ms}$ are a cause for concern and more frequent monitoring or the cessation of therapy is recommended in such cases. ${ }^{24,42}$

Other situations that warrant ECG monitoring include overdoses of medication with QT-prolonging potential, when more than one QTc-prolonging medication is prescribed in combination, when a patient experiences cardiovascular symptoms, in patients with cardiovascular disease, and in cases of electrolyte derangements. ${ }^{26,34,42}$ Some medications have specific ECG recommendations available. For instance, the Center for Substance Abuse and Mental Health Services
Administration (CSAT), an independent multidisciplinary expert panel, developed guidelines on cardiac safety recommendations for methadone prescribers. ${ }^{28}$ The guidelines recommend a pretreatment ECG for all patients prior to initiating methadone, a follow-up ECG within 30 days, and then annually thereafter or sooner if there is a change in dosage. Increased monitoring is recommended if a patient has a QT interval over $450 \mathrm{~ms}$. If the QT interval exceeds $500 \mathrm{~ms}$, discontinuation of methadone should be considered.

\section{Step 5: recommending strategies to minimize the likelihood of drug- induced TdP}

If cardiac risks are identified, the cardiac risk factors should be optimized and/or a drug with a more favorable risk profile should be chosen if possible. In case of structural heart disease, QT prolongation, electrolyte disturbances, or cardiac symptoms, referral to a cardiologist should be considered. ${ }^{34}$ Re-evaluation of the ECG and symptoms should take place within 1 or 2 weeks or at steady state (five times the drug half-life) after initiation of treatment with class 1 drugs or with class $3 / 4$ drugs if used in combination. ${ }^{34}$ Similarly, a significant increase in dose of these drugs necessitates re-evaluating symptoms and a new ECG. ${ }^{34}$

A QTc interval above $500 \mathrm{~ms}$ or an increment above $60 \mathrm{~ms}$ when compared with baseline is generally associated with a definite increased risk of $\mathrm{TdP}$ and should in most cases lead to discontinuation of the drug. ${ }^{34,47}$ It is suggested to consult a cardiologist if the QTc stays prolonged after discontinuing medication, if cardiovascular symptoms are present, or in case of pre-existing cardiac disease or when a strong family history exists. Several other QTc scenarios occurring during treatment also merit specialist consultation, such as in pediatric patients, in the elderly, and in frail (ie, hospitalized) individuals. ${ }^{48}$

\section{Discussion}

The literature review undertaken provides a comprehensive list of studies, reports, and guidelines for the assessment, monitoring, and management of drug-induced QTc prolongation in the psychiatric population. In order to facilitate the translation of evidence-based recommendations into practice, a stepped-care approach was used in the development of the algorithm to assist mental health clinicians in making decisions when medications known to increase the QTc interval are used.

In a similar algorithm developed by Fanoe et al, the risk of arrhythmia associated with various classes of psychotropic 
medications was described. ${ }^{34}$ We believe that our algorithm adds value to the one developed by Fanoe et al as it provides a stepped-care approach with a set of clinical questions that are intended to help in rationalizing the decision-making process. Fanoe et al did not recommend the use of a specific QTc risk scoring tool, and rather suggested seeking a cardiologist consultation when patients present with any positive risk factors for prolonged QTc. Our algorithm still supports cardiology consultation, especially in those whose risk score is $>7$ points. In 2002, the Cardiac Safety in Schizophrenia Group released a series of consensus statements on how to minimize the risks associated with significant QTc prolongation in people with schizophrenia. ${ }^{55}$ These, however, have not been updated since and consequently have no information on newer medications or on medications other than those used for the management of schizophrenia; thus, our algorithm is more inclusive of other psychiatric diagnoses and provides a more updated resource for clinicians. ${ }^{53}$

Common findings in the literature review which guided the development of this algorithm include the use of CredibleMeds ${ }^{\circledR}$ as an important evidence-based resource, as well as the importance of cardiac risk stratification in the assessment and management of drug-induced QTc prolongation. Studies have shown that prescribers do not routinely screen for cardiac risk factors in psychiatric patients. ${ }^{53,56,57}$ In addition, because ECG monitoring may not be possible or readily accessible in both outpatient and inpatient settings, or in all psychiatric facilities, the algorithm developed highlights the importance of assessing the associated risk factors as early as possible before making recommendations on the use of medications with QTc-prolonging risk, primarily those listed as Category $1-3$ by CredibleMeds ${ }^{\circledR}$ or those that are known inhibitors of the hERG IKr channel. ${ }^{11,49,53,56-58}$ Current research initiatives, such as the Comprehensive in vitro Proarrhythmia Assay (CiPA), are developing and validating a model to test the proarrhythmic risk of drugs by assessing the effect of drugs on multiple ion channels and integrating ECG analysis in early phase I clinical trials to better predict proarrhythmic risk. ${ }^{59}$ If successful, CiPA will 1) create a pathway for drugs with hERG block/QT prolongation to advance without intensive ECG monitoring in phase III trials if they have low proarrhythmic risk and 2) enable updating of drug labels to be more informative about proarrhythmic risk, not just QT prolongation. ${ }^{59}$

Despite the robustness of our literature review, the algorithm developed is not without limitations. The algorithm incorporates a tool to predict the risk of QTc prolongation that was developed by Tisdale et al and validated only in nonpsychiatric populations. ${ }^{42,44}$ Thus, it is uncertain how the risk scoring tool will perform in patients with psychiatric disorders who are known to be at higher risk of cardiac events regardless of the medications they are on. ${ }^{60}$ Future testing of this stepped-based algorithm with regard to its usefulness in guiding pharmacists and other clinicians in the decision-making process when medications are prescribed to mental health patients is necessary.

\section{Conclusion}

The algorithm developed provides a stepped approach for assessing and managing the risk of QTc prolongation when prescribing medications for patients with psychiatric disorders. The stepped approach described may also be appropriate when assessing drug-induced QTc prolongation risk in individuals without psychiatric disorders. Further investigations dedicated to the validation of this stepped-based algorithm are required, including face validation and the feasibility for its routine use by clinicians, including an evaluation of the outcome of its use over time.

\section{Acknowledgment}

An earlier version of this research was presented as a poster at the Canadaian Society of Hospital Pharmacists Annual Professional Practice Conference, in Toronto, Canada, from February 3-8, 2018. The abstract of this poster was published as part of the conference proceedings as follows: Zolezzi M, Chelung L. A literature-based algorithm for the assessment, management and monitoring of drug-induced QTc prolongation in the psychiatric population. Can J Hosp Pharm. 2018;71(1):66.

\section{Disclosure}

The authors report no conflicts of interest in this work.

\section{References}

1. Schwartz PJ, Woosley RL. Predicting the unpredictable: drug-induced QT prolongation and torsades de pointes. J Am Coll Cardiol. 2016; 67(13):1639-1650.

2. Ifteni P, Correll CU, Burtea V, Kane JM, Manu P. Sudden unexpected death in schizophrenia: autopsy findings in psychiatric inpatients. Schizophr Res. 2014;155(1-3):72-76.

3. Ray WA, Chung CP, Murray KT, Hall K, Stein CM. Atypical antipsychotic drugs and the risk of sudden cardiac death. N Engl J Med. 2009; 360(3):225-235.

4. Girardin F, Sztajzel J. Cardiac adverse reactions associated with psychotropic drugs. Dialogues Clin Neurosci. 2007;9(1):92-95.

5. Buckley NA, Sanders P. Cardiovascular adverse effects of antipsychotic drugs. Drug Saf. 2000;23(3):215-228.

6. Beach SR, Celano CM, Noseworthy PA, Januzzi JL, Huffman JC. QTc prolongation, torsades de pointes, and psychotropic medications. Psychosomatics. 2013;54(1):1-13. 
7. Malik M, Camm AJ. Evaluation of drug-induced QT interval prolongation: implications for drug approval and labelling. Drug Saf. 2001;24(5): 323-351.

8. Darpo B. Spectrum of drugs prolonging QT interval and the incidence of torsades de pointes. Eur Heart J. 2001;3(Suppl K):K70-K80.

9. Ching CK, Tan EC. Congenital long QT syndromes: clinical features, molecular genetics and genetic testing. Expert Rev Mol Diagn. 2006; 6(3):365-374.

10. Roden DM, Viswanathan PC. Genetics of acquired long QT syndrome. J Clin Invest. 2005;115(8):2025-2032.

11. Cubeddu LX. Iatrogenic QT Abnormalities and fatal arrhythmias: mechanisms and clinical significance. Curr Cardiol Rev. 2009;5(3):166-176.

12. Itoh $\mathrm{H}$, Crotti $\mathrm{L}$, Aiba $\mathrm{T}$, et al. The genetics underlying acquired long QT syndrome: impact for genetic screening. Eur Heart J. 2016;37(18): 1456-1464.

13. Trinkley KE, Page RL, Lien H, Yamanouye K, Tisdale JE. QT interval prolongation and the risk of torsades de pointes: essentials for clinicians. Curr Med Res Opin. 2013;29(12):1719-1726.

14. Witchel HJ, Hancox JC, Nutt DJ. Psychotropic drugs, cardiac arrhythmia, and sudden death. J Clin Psychopharmacol. 2003;23(1):58-77.

15. Silvestre JS, O’Neill MF, Prous JR. Evidence for a crucial modulating role of the sodium channel in the QTc prolongation related to antipsychotics. J Psychopharmacol. 2014;28(4):329-340.

16. Al-Khatib SM, Allen Lapointe NM, Kramer JM, et al. A survey of health care practitioners' knowledge of the QT interval. J Gen Intern Med. 2005;20(5):392-396.

17. Fongemie JM, Al-Qadheeb NS, Estes NA, et al. Agreement between ICU clinicians and electrophysiology cardiologists on the decision to initiate a QTc-interval prolonging medication in critically ill patients with potential risk factors for torsade de pointes: a comparative, casebased evaluation. Pharmacotherapy. 2013;33(6):589-597.

18. Ojero-Senard A, Benevent J, Bondon-Guitton E, et al. A comparative study of QT prolongation with serotonin reuptake inhibitors. Psychopharmacology. 2017;234(20):3075-3081.

19. Barbui C, Bighelli I, Carrà G, et al. Antipsychotic Dose Mediates the Association between Polypharmacy and Corrected QT Interval. PLoS One. 2016;11(2):e0148212.

20. Danielsson B, Collin J, Jonasdottir Bergman G, Borg N, Salmi P, Fastbom J. Antidepressants and antipsychotics classified with torsades de pointes arrhythmia risk and mortality in older adults - a Swedish nationwide study. Br J Clin Pharmacol. 2016;81(4):773-783.

21. Nosè M, Bighelli I, Castellazzi M, et al. Prevalence and correlates of QTc prolongation in Italian psychiatric care: cross-sectional multicentre study. Epidemiol Psychiatr Sci. 2016;25(6):532-540.

22. Schächtele S, Tümena T, Gaßmann KG, Fromm MF, Maas R. Co-prescription of QT-interval prolonging drugs: an analysis in a large cohort of geriatric patients. PLoS One. 2016;11(5):e0155649.

23. Poncet A, Gencer B, Blondon M, et al. Electrocardiographic screening for prolonged QT interval to reduce sudden cardiac death in psychiatric patients: a cost-effectiveness analysis. PLoS One. 2015;10(6): e0127213.

24. Rabkin SW. Impact of age and sex on QT prolongation in patients receiving psychotropics. Can J Psychiatry. 2015;60(5):206-214.

25. Takeuchi H, Suzuki T, Remington G, Uchida H. Antipsychotic polypharmacy and corrected QT interval: a systematic review. Can J Psychiatry. 2015;60(5):215-222.

26. Shah AA, Aftab A, Coverdale J. QTc prolongation with antipsychotics: is routine ECG monitoring recommended? J Psychiatr Pract. 2014; 20(3):196-206.

27. Girardin FR, Gex-Fabry M, Berney P, Shah D, Gaspoz JM, Dayer P. Drug-induced long QT in adult psychiatric inpatients: the 5-year crosssectional ECG Screening Outcome in Psychiatry study. Am JPsychiatry. 2013;170(12):1468-1476.

28. Katz DF, Sun J, Khatri V, et al. QTc interval screening in an opioid treatment program. Am J Cardiol. 2013;112(7):1013-1018.

29. Tran E, Dishman B. Citalopram-induced QTc prolongation: a brief review of the data. Ment Health Clin. 2012;2(6):139-141.
30. Wenzel-Seifert K, Wittmann M, Haen E. QTc prolongation by psychotropic drugs and the risk of Torsade de Pointes. Dtsch Arztebl Int. 2011;108(41):687-693.

31. Yang FD, Wang XQ, Liu XP, et al. Sex difference in QTc prolongation in chronic institutionalized patients with schizophrenia on long-term treatment with typical and atypical antipsychotics. Psychopharmacology. 2011;216(1):9-16

32. Wahidi N, Johnson KM, Brenzel A, de Leon J. Two sudden and unexpected deaths of patients with schizophrenia associated with intramuscular injections of antipsychotics and practice guidelines to limit the use of high doses of intramuscular antipsychotics. Case Rep Psychiatry. 2016;2016:9406813-14.

33. Chou R, Cruciani RA, Fiellin DA, et al. Methadone safety: a clinical practice guideline from the American Pain Society and College on Problems of Drug Dependence, in collaboration with the Heart Rhythm Society. J Pain. 2014;15(4):321-337.

34. Fanoe S, Kristensen D, Fink-Jensen A, et al. Risk of arrhythmia induced by psychotropic medications: a proposal for clinical management. Eur Heart J. 2014;35(20):1306-1315.

35. Pacciardi B, Mauri M, Cargioli C, et al. Issues in the management of acute agitation: how much current guidelines consider safety? Front Psychiatry. 2013;4:26.

36. de Hert M, Vancampfort D, Correll CU, et al. Guidelines for screening and monitoring of cardiometabolic risk in schizophrenia: systematic evaluation. Br J Psychiatry. 2011;199(2):99-105.

37. Martin JA, Campbell A, Killip T, et al. QT interval screening in methadone maintenance treatment: report of a SAMHSA expert panel. $J$ Addict Dis. 2011;30(4):283-306.

38. Nielsen J, Graff C, Kanters JK, Toft E, Taylor D, Meyer JM. Assessing QT interval prolongation and its associated risks with antipsychotics. CNS Drugs. 2011;25(6):473-490.

39. Fishman GI, Chugh SS, Dimarco JP, et al. Sudden cardiac death prediction and prevention: report from a National Heart, Lung, and Blood Institute and Heart Rhythm Society Workshop. Circulation. 2010; 122(22):2335-2348.

40. Modesto-Lowe V, Brooks D, Petry N. Methadone deaths: risk factors in pain and addicted populations. J Gen Intern Med. 2010;25(4): 305-309.

41. Institute for Safe Medication Practices Canada ${ }^{\circledR}$. Pharmacist Evaluation of QT Prolongation Risk and Recommendation. [Internet]; 2017. Available from: https://www.ismp-canada.org/ToolQit_QTprolongation/. Accessed September 03, 2018.

42. Tisdale JE. Drug-induced QT interval prolongation and torsades de pointes: Role of the pharmacist in risk assessment, prevention and management. Can Pharm J. 2016;149(3):139-152.

43. Jardin CG, Putney D, Michaud S. Assessment of drug-induced torsade de pointes risk for hospitalized high-risk patients receiving QT-prolonging agents. Ann Pharmacother. 2014;48(2):196-202.

44. Tisdale JE, Jaynes HA, Kingery JR, et al. Effectiveness of a clinical decision support system for reducing the risk of QT interval prolongation in hospitalized patients. Circ Cardiovasc Qual Outcomes. 2014;7(3): 381-390.

45. Haugaa KH, Bos JM, Tarrell RF, Morlan BW, Caraballo PJ, Ackerman MJ. Institution-wide QT alert system identifies patients with a high risk of mortality. Mayo Clin Proc. 2013;88(4):315-325.

46. Tisdale JE, Jaynes HA, Kingery JR, et al. Development and validation of a risk score to predict QT interval prolongation in hospitalized patients. Circ Cardiovasc Qual Outcomes. 2013;6(4):479-487.

47. Nachimuthu S, Assar MD, Schussler JM. Drug-induced QT interval prolongation: mechanisms and clinical management. Ther Adv Drug Saf. 2012;3(5):241-253.

48. Drew BJ, Ackerman MJ, Funk M. Prevention of Torsade de Pointes in hospital settings: A scientific statement from the American Heart Association and the American College of Cardiology Foundation, endorsed by the American Association of Critical-Care Nurses and the International Society for Computerized Electrocardiology. Circulation. 2010;121(8):1047-1060. 
49. CredibleMeds ${ }^{\circledR}$ [homepage on the Internet]. FAQs on QTdrugs lists, 2013. Available from: https://www.crediblemeds.org/everyone/ articlesbrochures-library/consumerfaq. Accessed September 3, 2018.

50. Woosley RL, Black K, Heise CW, Romero K. CredibleMeds.org: what does it offer? Trends Cardiovasc Med. 2018;28(2):94-99.

51. Pan SD, Zhu LL, Chen M, Xia P, Zhou Q. Weight-based dosing in medication use: what should we know? Patient Prefer Adherence. 2016; 10:549-560.

52. Luscombe DK. Factors influencing plasma drug concentrations. J Int Med Res. 1977;5(1 Suppl):82-97.

53. Boszko M, Stanciu CN. Survey of EKG monitoring practices: a necessity or prolonged nuisance? Am J Psychiatry Residents' Journal. 2017;11(3):6-9.

54. Castelletti S, Dagradi F, Goulene K, et al. A wearable remote monitoring system for the identification of subjects with a prolonged QT interval or at risk for drug-induced long QT syndrome. Int J Cardiol. 2018;266: 89-94.

55. Ames D, Camm J, Cook P, et al. Minimizing the risks associated with QTc prolongation in people with schizophrenia. A consensus statement by the Cardiac Safety in Schizophrenia Group. Encephale. 2002; 28(6 Pt 1):115-124
56. Girgis SJ, Maroney ME, Liu MT. Evaluation of the use of electrocardiogram monitoring in patients on psychotropic medications that have a risk of QT prolongation. Ment Health Clin. 2016;6(4): 171-177.

57. Warnier MJ, Rutten FH, Souverein PC, de Boer A, Hoes AW, de Bruin ML. Are ECG monitoring recommendations before prescription of QT-prolonging drugs applied in daily practice? The example of haloperidol. Pharmacoepidemiol Drug Saf. 2015;24(7):701-708.

58. Vandael E, Foulon V. Drug-induced QTc-prolongation: risk management in a community pharmacy. Journal of the Malta College of Pharmacy Practice. 2017;23(3):7-12.

59. Vicente J, Zusterzeel R, Johannesen L, et al. Mechanistic modelinformed proarrhythmic risk assessment of drugs: review of the "CiPA" initiative and design of a prospective clinical validation study. Clin Pharmacol Ther. 2018;103(1):54-66.

60. Manu P, Kane JM, Correll CU. Sudden deaths in psychiatric patients. J Clin Psychiatry. 2011;72(7):936-941.

\section{Publish your work in this journal}

Neuropsychiatric Disease and Treatment is an international, peerreviewed journal of clinical therapeutics and pharmacology focusing on concise rapid reporting of clinical or pre-clinical studies on a range of neuropsychiatric and neurological disorders. This journal is indexed on PubMed Central, the 'PsycINFO' database and CAS, and is the official journal of The International Neuropsychiatric Association (INA). The manuscript management system is completely online and includes a very quick and fair peer-review system, which is all easy to use. Visit http://www.dovepress.com/testimonials.php to read real quotes from published authors. 